\title{
COMUNICACIÓN
}

\section{Primer registro de Amblyomma longirostre (Acari: Ixodidae) en Uruguay}

\author{
JOSÉ M. VENZAL*, OSCAR CASTRO*, SANTIAGO CLARAMUNT** y ALBERTO A. GUGLIELMONE***
}

\section{FIRST RECORD OF Amblyomma longirostre (ACARI: IXODIDAE) IN URUGUAY}

Amblyomma longirostre is recorded for the first time in Uruguay. Nymphs of this species were found on a resident bird, Phylloscartes ventralis (Passeriformes: Tyrannidae), from a locality in which a potential host to adults ticks, Sphiggurus spinosus (Rodentia: Erethizontidae), also inhabits. From these facts, it is concluded that A. longirostre is, probably, resident in Uruguay. Also, this is the southernmost record for this species.

Key words: Ixodidae, Amblyomma longirostre, birds, distribution, Uruguay.

\section{INTRODUCCIÓN}

El género Amblyomma (Acari: Ixodidae) posee una distribución principalmente tropical y subtropical $^{1}$, y está representado por aproximadamente 122 especies $^{2}$.

Amblyomma longirostre es una especie cuyas formas adultas parasitan principalmente roedores de la familia Erethizontidae, aunque ocasionalmente también se han hallado en monos del género Cebus y en el hombre. Las ninfas se han hallado alimentándose en Artibeus (Chiroptera: Phyllostomidae) y Sciurus (Rodentia: Sciuridae), así como en una amplia variedad de aves en América Central, América del Sur y Estados Unidos $^{3,4}$.

La larva de esta especie no ha sido descrita ${ }^{2}$, aunque probables larvas fueron encontradas en aves de Brasil ${ }^{5}$ y en Sciurus granatensis de Venezuela ${ }^{4}$. La ninfa fue descripta por microscopía electrónica de barrido ${ }^{6}$.

Su distribución se extiende desde Panamá a
$\mathrm{Brasil}^{4}$, se le ha a registrado como presente en la Provincia de Misiones, Argentina, sobre Coendu spinosus (Rodentia: Erethizontidae). ${ }^{7}$ Aunque autores no mencionan la presencia de $A$. longirostre en Rio Grande do Sul, Brasil ${ }^{8}$; otros la encontraron sobre Coendu villous en ese estado del sur brasilero 9 . El hallazgo de ninfas en aves migratorias es común en los Estados Unidos de Norteamérica pero no se la considera establecida en este país. ${ }^{6}$ La presencia de A. longirostre no fue registrada precedentemente en el Uruguay, y en este artículo comunicamos su presencia en donde suponemos es una especie residente.

\section{MATERIAL Y MÉTODOS}

El material de estudio consistió en un lote compuesto por dos ninfas ingurgitadas de Amblyomma sp. conservadas en alcohol $70^{\circ}$. Estas ninfas fueron extraídas de la zona auricular de un Phylloscartes ventralis (Passeriformes: Tyrannidae). El ave fue capturada en una red de

\footnotetext{
* Departamento de Parasitología Veterinaria, Facultad de Veterinaria, Universidad de la República, Av. Alberto Lasplaces 1550, 11600 Montevideo, Uruguay. E-mail: dpvuru@adinet.com.uy

** Museo Nacional de Historia Natural, Casilla de Correo 399, 11000 Montevideo, Uruguay.

*** Instituto Nacional de Tecnología Agropecuaria, Estación Experimental Agropecuaria Rafaela, Casilla de Correo 22, 2300 Rafaela, Santa Fe, Argentina.
} 
niebla en el interior del bosque galería en Gajo del Lunarejo, cercano a la localidad de Masoller $\left(31^{\circ} 04^{\prime} \mathrm{S} 56^{\circ} 00^{\prime} \mathrm{W}\right)$, Departamento de Rivera, Uruguay, el 8 de enero de 2000 por S. Claramunt y G. Rocha, y depositado bajo el número 5.888 en la colección ornitológica del Museo Nacional de Historia Natural (Montevideo, Uruguay). Para su clasificación, el material fue analizado utilizando un microscopio electrónico de barrido JEOL modelo JSM-5900LV, trabajando en bajo vacío para evitar el uso de la técnica de metalización y preservar de esa forma los ejemplares intactos. Como material comparativo fueron utilizadas ninfas de Amblyomma triste, A. tigrinum, A. dubitatum, A. aureolatum que se encuentran depositadas en la colección del Departamento de Parasitología Veterinaria, Facultad de Veterinaria Montevideo, Uruguay, y

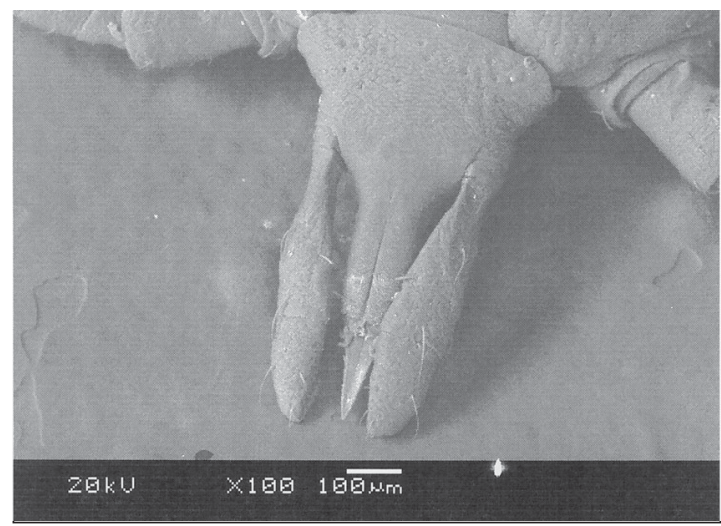

Figura 1. A. longirostre (ninfa dorsal), capitulum.

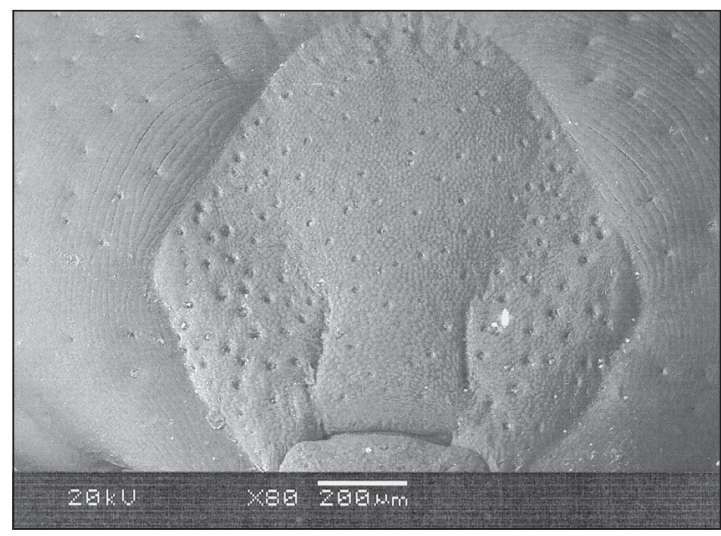

Figura 3. A. longirostre (ninfa dorsal), escudo. las descripciones de los estadios ninfales de $A$. neumanni ${ }^{10}$ y A. longirostre ${ }^{6}$

\section{RESULTADOS}

Las imágenes obtenidas de las ninfas muestran un capitulum largo con base triangular (dorsal) (Figura 1), hipostoma de forma lanceolada con fórmula dentaria 2/2 (Figura 2), escudo alargado con numerosas puntuaciones distribuidas en forma regular, siendo más profundas en la zona antero lateral (Figura 3), y la coxa I con dos espinas cortas, siendo la externa mayor que la interna (Figura 4). La morfología de las ninfas coincide con la descrita para ninfas de A. longirostre ${ }^{6}$ y se separa claramente, por la morfología lanceolada de su hipostoma, de las ninfas de las demás especies de Amblyomma citadas para Uruguay.

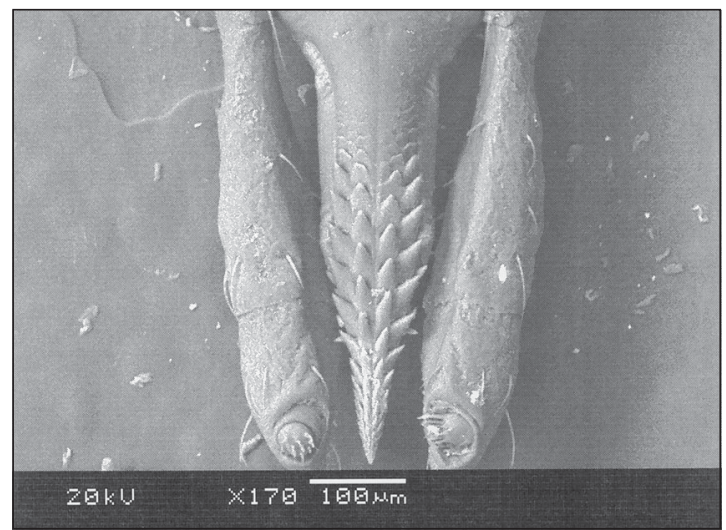

Figura 2. A. longirostre (ninfa ventral), palpos e hipostoma con dentición 2/2.

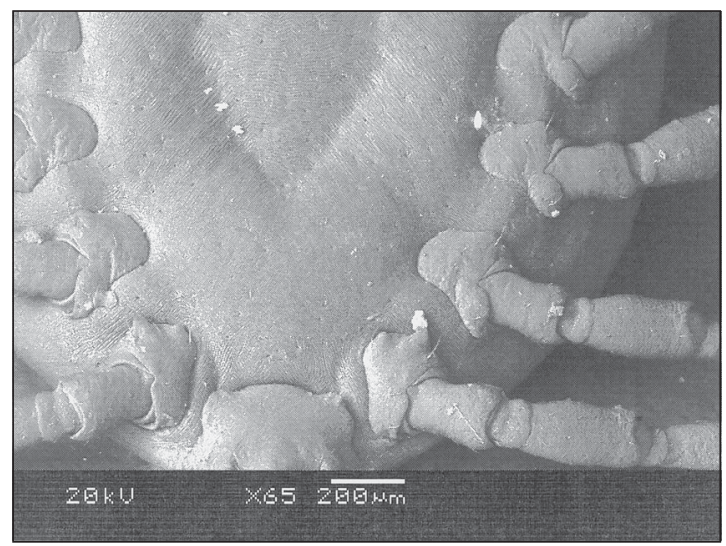

Figura 4. A. longirostre (ninfa ventral), coxas I, II, III y IV (de abajo hacia arriba). 


\section{DISCUSIÓN}

El hallazgo de A. longirostre en el Uruguay es el más austral registrado hasta la fecha. Este hallazgo también corresponde a la primera cita de esta especie de Amblyomma para el Uruguay. $\mathrm{Su}$ hospedador, $P$. ventralis, es un ave no migratoria residente en el país ${ }^{11}$, con hábitos sedentarios (Claramunt, S., obs. pers.). En la región de hallazgo habita también Sphiggurus spinosus, un hospedador natural de los adultos de A. longirostre. Es, por lo tanto, probable que A. longirostre sea una especie residente en Uruguay, lo cual se confirmará con el hallazgo de esos estadios sobre el hospedador mencionado.

\section{RESUMEN}

Se informa por prmera vez la presencia de Amblyomma longirostre en Uruguay. Se encontraron ninfas de esta especie en un ave (Phylloscartes ventralis) de una localidad en que habita un roedor potencial huésped para esta garrapata adulta, por lo que se concluye que es probable que ella sea residente en el país. Para la garrapata esta ubicación geográfica sería la más autral descripta.

\section{REFERENCIAS}

1.- COOLEY R A, KOHLS GM. The genus Amblyomma (Ixodidae) in the United States. J Parasitol 1944; 30: 77-111.

2.- CAMICAS J L, HERVY J P, ADAM F, MOREL P C. Les tiques du monde. Éditions de l'Orstom, Institut Français de Recherche Scientifique pour le Développement en Coopération, Paris, 1998. 233 pp.
3.- FAIRCHILD G B, KOHLS G M, TIPTON V J. The ticks of Panama (Acarina: Ixodoidea). En: Ectoparasites of Panama, R.L. Wenzel y V.J. Tipton Eds. Field Museum of Natural History, Chicago, 1966; 167-219.

4.- JONES E K, CLIFFORD C M, KEIRANS J E, KOHLS G M. Ticks of Venezuela (Acarina: Ixodoidea) with a key to the species of Amblyomma in the Western Hemisphere, Brigham Young Univ Sci Bull 1972; 17: $1-40$.

5.- ARAGAO H B. Ixodidas brasileros e de alguns paises limitrofes. Mem Ins Oswaldo Cruz 1936; 31: 795-843.

6.- KEIRANS J E, DURDEN LA. Illustrated key to nymphs of the tick genus Amblyomma (Acari: Ixodidae) found in the United States. J Med Entomol 1998; 35: 489-95.

7.- BOERO J J, DELPIETRO H. Amblyomma longirostre Koch, 1844 (Acarina: Ixodidae). Primera comprobación en la Republica Argentina. Rev Méd Vet (Buenos Aires) 1970; 51: 335-7.

8.- EVANS D E, MARTINS J R, GUGLIELMONE A A. A review of the ticks (Acari: Ixodida) of Brazil, their hosts and geographical distribution. 1. The state of Rio Grande do Sul, southern Brazil. Mem Inst Oswaldo Cruz 2000; 95: 453-70.

9.- OLIVEIRA C M B, RIBEIRO V L S, GONÇAL-VES I P D. Amblyomma longirostre (Koch, 1844) parasitando ouriço-cacheiro (Coendu villosus) no Rio Grande do Sul. Arq Fac Vet UFRGS 1997; 25 (2): 103-4.

10.- ESTRADA PEÑA A, GUGLIELMONE A A, MANGOLD A J, CASTELLÁ J. A description of Amblyomma tigrinum Koch, A. neumanni Ribaga and A. testudinis (Conil) inmatures (Acarina: Ixodidae). Folia Parasitol 1993; 40: 147-53.

11.- AZPIROZ A B. Aves del Uruguay. Lista e introducción a su biología y conservación. Aves Uruguay, Montevideo, 2001. 104 pp.

Agradecimientos: Al Lic. Alejandro Márquez y Prof. Jorge Troccoli de la Unidad de Microscopía Electrónica de Barrido, Facultad de Ciencias, Montevideo, Uruguay. A Gabriel Rocha por la ayuda en el campo durante la excursión ornitológica al Lunarejo. 